\title{
Flora do Rio de Janeiro: Lentibulariaceae
}

\author{
Flora of Rio de Janeiro: Lentibulariaceae
}

Paulo Cesar Baleeiro ${ }^{1,3}$, Andréia Donza Rezende Moreira ${ }^{2}$, Nílber Gonçalves da Silva ${ }^{2}$ \& Claudia Petean Bove ${ }^{2}$

\begin{abstract}
Resumo
O presente estudo tem como objetivo contribuir para o conhecimento das espécies de Lentibulariaceae ocorrentes no estado do Rio de Janeiro. O trabalho tem por base a análise morfológica de materiais depositados em herbários e coletas de campo, além da compilação de dados de literatura. Foram registrados dois gêneros e 20 espécies. Chave para identificação, descrições, ilustrações, dados sobre floração e frutificação, hábitat, fenologia e distribuição geográfica das espécies são apresentados.
\end{abstract}

Palavras-chave: Utricularia, Genlisea, florística, planta carnívora, taxonomia.

\begin{abstract}
This study focuses on the Lentibulariaceae found in the state of Rio de Janeiro. It is based on a morphological analysis of herbaria collections, as well as on a review of the relevant literature and on collections in the field. A total of two genera and 20 species were recorded for the state. An identification key, descriptions, illustrations, flowering and fruiting data, habitat and species distribution are also provided.
\end{abstract}

Key words: Utricularia, Genlisea, floristic inventories, carnivorous plant, taxonomy.

\section{Lentibulariaceae Rich.}

Ervas anuais ou perenes; carnívoras; terrestres, aquáticas, reófitas, litófitas ou epífitas. Raízes ausentes, rizoide geralmente presentes. Folhas no escapo, estolão ou rizoide; filiformes a circulares, raro peltadas, margem inteira; folhas dispostas em rosetas adaptadas para captura de presas ou modificadas em armadilhas. Inflorescência uniflora a racemosa, escapo glabro, piloso e/ou glandular; escamas, brácteas e bractéolas basifixas ou peltadas. Flores bissexuadas, zigomorfas, diclamídeas; 2, 4-5 sépalas persistentes, margem inteira a profundamente fimbriada, nervuras ausentes a proeminentes; 2 estames epipétalos; corola branca, creme, amarela, laranja, rosa, lilás, violeta, vermelha ou azul, com ou sem mácula, bilabiada, gibosa, calcarada; ovário súpero, glabro ou glandular; placentação central-livre, estigma bilabiado. Fruto capsular globoso, elipsóide ou cilíndrico; sementes 1-muitas, forma variada.

Família cosmopolita com ca. 330 espécies distribuídas nos gêneros Genlisea A.St.-Hil., Pinguicula L. e Utricularia L. No Brasil ocorrem Genlisea e Utricularia, totalizando 82 espécies sendo 26 endêmicas (BFG 2015). No Rio de Janeiro são registrados ambos os gêneros e 20 espécies. Todas as ocorrências apontadas na Lista do Brasil para o estado do Rio de Janeiro (BFG 2015) são corroboradas, exceto Utricularia amethystina Salzm. ex A.St.-Hil. \& Girard; e ausência do registro de $U$. simulans Pilg. e $U$. olivaceae C. Wright ex Griseb. para o estado na referida lista.

\footnotetext{
${ }^{1}$ Universidade de São Paulo, Inst. Biociências, Cidade Universitária, 05508-900, São Paulo, SP, Brasil.

${ }^{2}$ Universidade Federal do Rio de Janeiro, Depto. Botânica, Museu Nacional, São Cristóvão, 20940-040, Rio de Janeiro, RJ, Brasil.

${ }^{3}$ Autor para correspondência: paulobaleeiro@gmail.com
} 


\section{Chave para os gêneros}

1. Cálice composto por cinco sépalas 1. Genlisea

1'. Cálice composto por duas sépalas. 2. Utricularia

\section{Genlisea A.St.-Hil.}

Ervas terrestres a aquáticas fixas. Caule presente ou inconspícuo. Folhas em rosetas geralmente densas, obovadas a circulares, inteiras, multinérveas; rizófilo (armadilha) em forma de "Y". Inflorescência racemosa, simples, escapo geralmente híspido ou glandular, raro glabro; escamas quando presentes, basifixas; bráctea basifixa, não auriculada, margem inteira; duas bractéolas inseridas na base do pedicelo junto à bráctea; bráctea estéril ausente; pedicelo ereto em flor e fruto, híspido, glandular ou glabro; cinco sépalas, subiguais, glabras ou tricomas simples e/ou glandulares presentes. Flores amarelas, violáceas, raro esbranquiçadas; giba normalmente inconspícua, híspida, glandular ou glabra; ovário globoso, híspido, glandular ou glabro.

Gênero com 27 espécies distribuídas na América Central, América do Sul e África. No Brasil são registradas 14 espécies, sendo nove endêmicas; apenas uma ocorre no estado do Rio de Janeiro.

\subsection{Genlisea aurea A.St.-Hil., Voy. Distr. Diam. 2:} 429. 1833.

Fig. 1a

Erva terrestre. Caule $20 \times 1,5-2 \mathrm{~mm}$. Folhas (8-)15-30 mm, espatuladas; rizófilos até $3,5 \mathrm{~cm}$ compr. Inflorescência laxa, tricomas glandulares abundantes, $100-360 \times 0,7-1 \mathrm{~mm}$; escama ovada a largo-ovada, tricomas glandulares no escapo, escama, bráctea, sépala, pedicelo e fruto; bráctea estreito-ovada a ovada; bractéolas lanceoladas. Flores amarelas; 15-22 mm compr., pedicelo 10-15 mm compr.; sépalas lanceoladas a estreitoovadas, margem inteira, nervuras inconspícuas, 3-4 mm compr.; lábios da corola inteiros, ou inferior levemente 3-lobado; calcar estreitamente cilíndrico a partir de uma base cônica, ápice obtuso, até três vezes maior que o lábio inferior. Cápsula globosa. Material examinado: Teresópolis, Serra dos Órgãos, Campo das Antas, 2.100 m, 2.V.1931, fl. e fr., A.C. Brade 10777 (R); 2.100 m, 27.II.1933, fl. e fr., A.C. Brade 12481 (R); 2.100 m, 27-30.III.1883, fl., J. Saldanha (R 97218); 20.I.1887, fl., A. Glaziou 16233 (R).

Material adicional: GOIÁS: Alto Paraíso de Goiás, Parna Chapada dos Veadeiros, 11.VI.2010, fl., C.P. Bove 2207 (R).

Endêmica do Brasil, encontrada na Bahia, Espírito Santo, Goiás, Mato Grosso, Minas Gerais, Paraná, Rio de Janeiro (O18; O19), Santa Catarina, São Paulo e Tocantins.

\section{Utricularia L., Sp. Pl. 1: 18. 1753.}

Rizoides e estolões geralmente presentes. Folhas uni a multinérveas; folha modificada em vesícula (utrículo), composta de uma abertura e geralmente dois apêndices dorsais. Inflorescência simples, geralmente glabra. Flores amarelas, brancas a lilases, com ou sem mácula; casmógamas, menos frequente cleistógamas; pedicelo glabro; duas sépalas subiguais a desiguais, glabras ou papilosas, margem inteira a profundamente laciniada, nervuras ausentes a proeminentes; lábio superior da corola geralmente ovado ou largo-ovado, menor que o inferior, geralmente transverso-elíptico. Cápsula globosa a elipsóide.

Gênero com 220 espécies, sendo 68 ocorrentes no Brasil (19 endêmicas). No Rio de Janeiro são encontradas 19 espécies, sendo Utricularia geminiloba endêmica para o estado.

\section{Chave para identificação das espécies}

1. Bráctea peltada (basoluta)

2. Corola lilás, bractéolas e folhas peltadas presentes

2.12. Utricularia pubescens

2'. Corola amarela, bractéolas e folhas peltadas ausentes

3. Nervuras do cálice proeminentes convergentes no ápice

2.19. Utricularia triloba

3'. Nervuras do cálice não proeminentes e não convergentes no ápice

4. Corola até $6 \mathrm{~mm}$ compr.

4'. Corola com mais de $6 \mathrm{~mm}$ compr.

2.13. Utricularia pusilla

1'. Bráctea basifixa

2.16. Utricularia subulata 
5. Bractéolas ausentes ......

6. Corola amarela .....

7. Pedicelo ereto na flor e fruto

7'. Pedicelo ereto na flor e reflexo no fruto

6'. Corola rosa, lilás ou branca.

8. Folhas filiformes divididas em dois segmentos primários, dicotomicamente ramificadas; inflorescência 1-20 cm compr., corola 6-8 mm compr., rosa ou lilás .....

9. Calcar menor que o lábio inferior da corola; flor cleistógama na base do escapo com pedicelo reflexo 2.5. Utricularia hydrocarpa

9'. Calcar igual ou levemente maior que o lábio inferior da corola; flor cleistógama ausente

2.10. Utricularia poconensis

8'. Folhas ausentes; inflorescência ca. $0,5 \mathrm{~mm}$ compr. ou aparentemente ausente, corola 1,5-3 mm compr., branca

2.9. Utricularia olivacea

5'. Bractéolas presentes

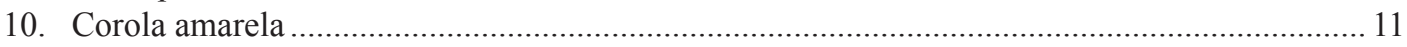

11. Brácteas, bractéolas e escamas de margem fimbriada ou denteada

2.15. Utricularia simulans

11'. Brácteas, bractéolas e escamas de margem inteiras ou apenas uma delas fimbriada........... 12 12. Sépalas com margem erosa-denticulada ...........................2.11. Utricularia praelonga 12'. Sépalas com margem inteira .............................................2.1. Utricularia erectiflora

10'. Corola roxa ou branca 13

13. Bractéolas unidas à bráctea na base

14. Corola $12 \mathrm{~mm}$ compr. 14

14'. Corola 6-10 mm compr.

2.17. Utricularia tricolor

13'. Bractéolas livres

2.18. Utricularia tridentata

15. Folhas peltadas 15

15 '. Folhas não peltadas

2.7. Utricularia nelumbifolia

16. Lâminas lanceoladas 16

16'. Lâminas reniformes ou ovadas 2.6. Utricularia longifolia

17. Folhas ovadas ou largo-ovadas. 17

17'. Folhas reniformes 2.3. Utricularia geminiloba

18. Corola $0,9-1,6 \mathrm{~cm}$ compr. 18'. Corola 2,1-4 cm compr. 2.8. Utricularia nephrophylla 2.14. Utricularia reniformis

2.1. Utricularia erectiflora A.St.-Hil. \& Girard, Compt. Rend. Hebd., Séances Acad. Sci., Ser. D. 7: 870. 1838 .

Fig. 1b-c

Erva terrestre ou paludosa. Rizoides e estolões utrículiferos. Folhas no estolão, lineares, uninérveas, até $1,5 \mathrm{~cm}$ compr. Inflorescência racemosa, glabra, até $25 \mathrm{~cm}$ compr.; escamas basifixas, ovadas a elípticas, margem inteira; bráctea semelhante às escamas; bractéolas lanceoladas, mesmo tamanho da bráctea, margem inteira. Flor amarela, até $1 \mathrm{~cm}$ compr.; pedicelo ereto na flor e fruto; sépalas subiguais, glabras, inteiras, largo-ovadas, base decurrente, ca. $0,5 \mathrm{~cm}$ compr.; lábio superior da corola menor que a sépala; lábio inferior com ápice emarginado; calcar alongado, subulado, maior que o lábio inferior. Cápsula elipsóide ou globosa.
Material selecionado: Araruama, Praia do Sossego, alagado próx. às margens da lagoa de Araruama ca. de $14 \mathrm{~km}$ da Rod. Amaral Peixoto (entrada para Praia Seca), 7.III.1999, fl. e fr., R.M. Lisboa \& C.B. Moreira 19 (R). Cabo Frio, road between Araruama lagoon and the main road Cabo Frio-Arraial do Cabo (22 ${ }^{\circ} 55^{\prime} \mathrm{S}$; 42 $\left.{ }^{\circ} 5^{\prime} \mathrm{W}\right)$, 16.VIII.1953, fl. e fr., Segadas-Vianna et al. 857 (R). Carapebus, Lagoa Comprida, 30.IX.1994, fl., C.P. Bove et al. 456 (R). Macaé, Lagoa de Carapebus, 10.X.1979, fl., D. Araujo 3307 (GUA). Maricá, Barra de Maricá, 27.IX.1988, fl. e fr., R. Marquete 148 (RB). Rio de Janeiro, Restinga de Jacarepaguá, 19.V.1968, fl., M.C. Viana (GUA 06056).

Ocorre do Sul do México à América do Sul (exceto Peru, Chile, Paraguai, Uruguai e Argentina). No Brasil tem ampla distribuição. No Rio de Janeiro é encontrada na Restinga (N30, N31, T20, T24, T27, U16). Distingue-se pelo lábio inferior da corola tipicamente galeado, calcar divergente e base das sépalas decorrente. 

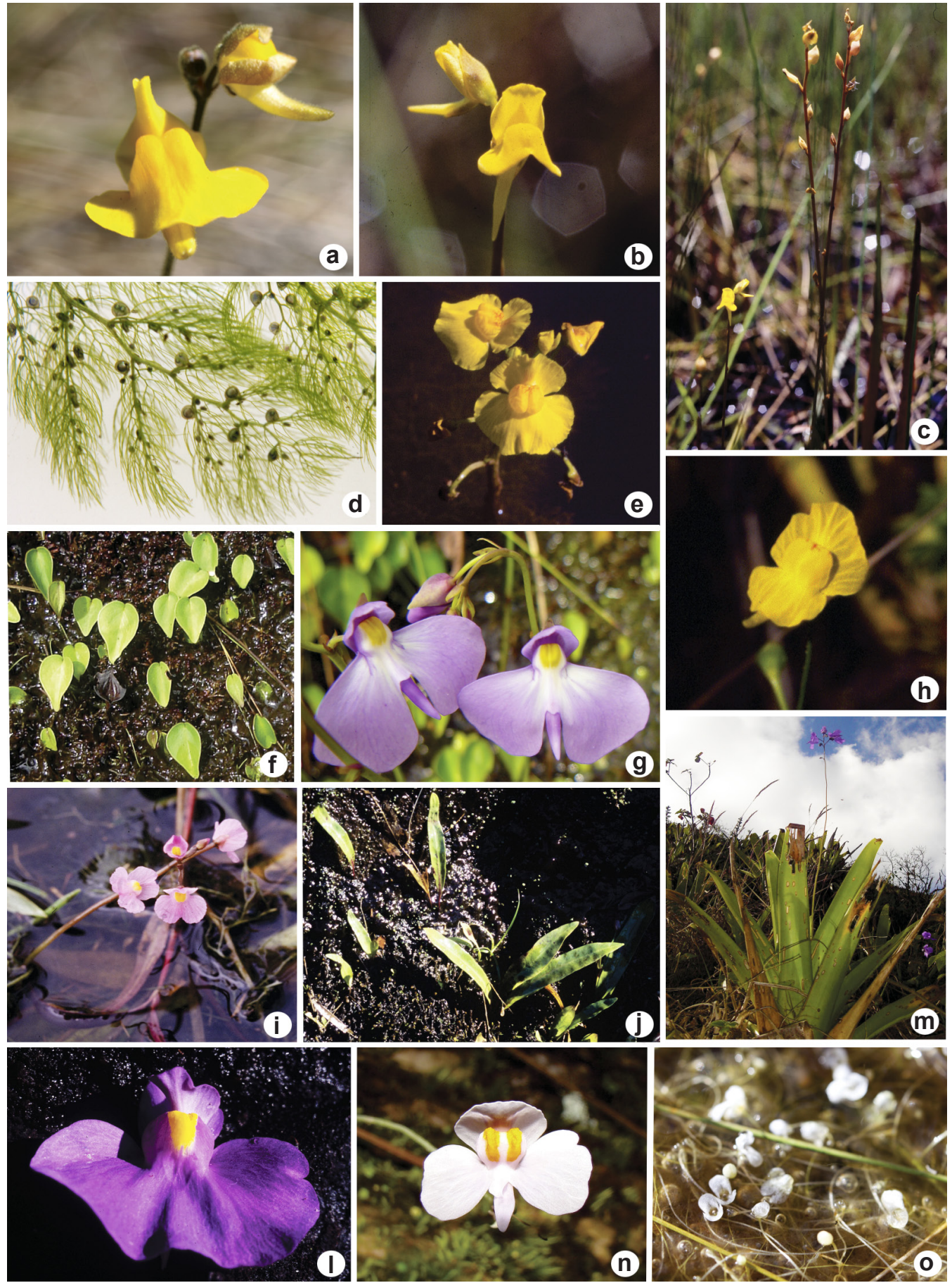

Figura 1 - a. Genlisea aurea - flor (Bove et al. 2207). b-c. Utricularia erectiflora - b. flor; c. hábito e frutos (Bove et al. 456). d-e. Utricularia foliosa - d. folha com utrículos; e. flor (Bove et al. 1992). f-g. Utricularia geminiloba f. folhas; g. flores (Rivadavia s/n). h. Utricularia gibba - flor (Bove et al. 400). i. Utricularia hydrocarpa - hábito (Bove et al. 301). j-1. Utricularia longifolia - j. folha; 1. flor (Bove et al. 86). m. Utricularia nelumbifolia - hábito. n. Utricularia nephrophylla - flor. o. Utricularia olivacea - hábito (Bove et al. 1592).

Figure 1 - a. Genlisea aurea - flower (Bove et al. 2207). b-c. Utricularia erectiflora - b. flower; c. fruit (Bove et al. 456). d-e. Utricularia foliosa - d. leaf with traps; e. flower (Bove et al. 1992). f-g. Utricularia geminiloba - f. leaves; g. flower. h. Utricularia gibba - flower (Bove et al. 400). i. Utricularia hydrocarpa - habit (Bove et al. 301). j-1. Utricularia longifolia - j. leaf; 1. flower (Bove et al. 86). m. Utricularia nelumbifolia - habit. n. Utricularia nephrophylla - flower. o. Utricularia olivacea - habit (Bove et al. 1592). 
2.2. Utricularia foliosa L., Sp. Pl. 1: 18. 1753. Fig. 1d-e

Erva aquática submersa, robusta. Rizoides ausentes. Estolões conspícuos. Folhas dimórficas, multipinadas, ramos capilares, até $55 \mathrm{~cm}$ compr., quando muito ramificadas poucos a nenhum utrículo, quando pouco ramificadas, muitos utrículos. Inflorescência racemosa, robusta, até $38 \mathrm{~cm}$ compr.; escamas basifixas, ovadas; brácteas semelhantes às escamas; bractéolas ausentes. Flores amarelas, 1,5-3 cm compr., agrupadas quando jovens e esparsas na maturidade; pedicelo ereto na flor e reflexo no fruto; sépalas subiguais, glabras, inteiras, largo-ovadas; lábio inferior da corola maior e geralmente bilobado, giba proeminente com nervuras em tons vináceos ou avermelhados; calcar levemente menor que o lábio inferior, ápice bífido. Cápsula globosa.

Material selecionado: Cabo Frio, Restinga de Cabo Frio, 15.VIII.1966, fl. e fr., D. Sucre 1017 (HB); Campos dos Goytacazes, Lagoa Feia, Coroa do Antonio, I.1985, fl., M.B. Casari et al. 743 (GUA). Carapebus, Lagoa de Jurubatiba, 13.IX.2005, fl. e fr., C.P. Bove et al. 1598 (R). Itaguaí, Estrada de Itaguaí, 29.IV.1963, fl. e fr., C. Pereira 7596 (HB); Macaé, Lagoa Comprida, 27.IV.1982, fl. e fr., D. Araujo et al. 4995 (GUA); Maricá, Restinga alagada próximo a S. José do Imbassaí, 23.XI.1983, fl. e fr., C. Farney \& E. Landolt 378 (RB); Petrópolis, lagoa no interior do Km 29 da Estrada Rio-Petrópolis, II.1938, fl. e fr., B. Lutz 1066 (R); Quissamã, estrada para Lagoa Pires, 29.IV.2009, fl. e fr., C.P. Bove et al. 1992 (R). Rio de Janeiro, 13.IV.1938, fl. e fr., A. Passarelli 11 (R); São Francisco de Itabapoana, Gargaú, 21.VIII.2003, C.N. Fraga 1028 (RB); Saquarema, Loteamento Villatur saquarema, APA restinga de Massambaba, Reserva Ecológica Estadual de Jacarepiá, Lagoa de Jacarepiá, 22055'14,2"S; 42²5'28,3"W, 28.IX.2008, fl. e fr., A.A.M. Barros \& C.E. Jascone 3357 (RFFP); Silva Jardim, Reserva Biológica de Poço das Antas, próximo à represa Juturnaíba, 5.XI.1982, fl., G. Martinelli 8819 (RB).

Ocorre na África e Américas. No Brasil tem ampla distribuição. No Rio de Janeiro ocorre em H36, L35, N30, N31, P17, Q25, T11, T20, T23, T27, U16. Distingue-se das demais espécies submersas ocorrentes no Estado pelo estolão achatado e folhas longas e dimórficas. A inflorescência congesta com pedicelo ereto em flor e laxa com pedicelo reflexo em fruto são características da espécie.

2.3. Utricularia geminiloba Benj. in Martius Fl. Bras. 10: 242. 1847.

Fig. 1f-g

Erva litófita. Rizoides ausentes. Estolões presentes. Folhas ao longo dos estolões, 0,3-2,9 cm compr., ovadas a largo-ovadas, não peltadas, multinérveas. Inflorescência glabra; 15-34 cm compr.; escamas, bráctea e bractéolas basifixas, não auriculadas, de ovadas a lanceoladas, margem inteira; bractéolas livres. Flores violáceas, 1,8-3,2 cm compr., pedicelo ereto na flor e no fruto; sépalas subiguais, glabras, $0,6-1 \mathrm{~cm}$ compr.; lábio superior da corola inteiro, inferior 3-lobado, giba conspícua; calcar aproximadamente do mesmo tamanho que o lábio inferior. Cápsula globosa.

Material selecionado: Angra dos Reis, 29.IX.1964, fl., Z.A. Trinta 891 \& E. Fromm-Trinta 1967 (HB). Itatiaia, III.1937, fl., A.C. Brade 15643 (RB). Macaé, Frade de Macaé, 17.VI.1937, fl., A.C. Brade 15856 (RB). Nova Friburgo, Mury, Macaé de Cima, nascente do Rio das Flores, matas remanescentes da Floresta Pluvial, Tropical Costeira, 25.X.1986, fl., G. Martinelli 11804 (RB). Petrópolis, Araras, morro Bolo de Milho, ca. 700-800 m, 27.IV.1968, fl. e fr., D. Sucre 2787 \& P.I.S. Braga 627 (HB). Rio de Janeiro, encosta Pico da Tijuca, 3.VII.1957, fl. e fr., H.E. Strang 48 (R). Santa Maria Madalena, Parque Estadual do Desengano, Pedra do Desengano, 30.VI.1989, fl., vertentes NE e SE/S, $G$. Martinelli 13387 (RB). Teresópolis, entrada da cidade de Teresópolis, em paredão úmido, 19.X.2010, fl. e fr., P.C. Baleeiro et al. $78(\mathrm{R})$; estrada Rio-Teresópolis km 87, A. Donza et al. 136 (R).

Endêmica do estado do Rio de Janeiro (L29, N27, O18, O24, P4, P17, T6, U16). Caracteriza-se pelo formato das folhas e tamanho do calcar.

\subsection{Utricularia gibba L., Sp. Pl. 1: 18. 1753.}

Fig. $1 \mathrm{~h}$

Erva submersa ou paludosa. Rizoides presentes ou não. Estolões utriculíferos livres ou fixos, muito ramificados. Folhas presentes ou não, simples a multipartidas, até $1,5 \mathrm{~cm}$ compr. Inflorescência racemosa, até $10 \mathrm{~cm}$ compr.; escamas quando presentes basifixas, depressoovadas a transversalmente oblongas; brácteas semelhantes às escamas; bractéolas ausentes. Flores amarelas com nervuras castanho-avermelhadas, 1 cm compr.; pedicelo ereto na flor e fruto; sépalas subiguais, glabras, inteiras, largo-elípticas; lábios da corola semelhantes, depresso-ovados, elípticos ou arredondados, inteiros ou levemente lobados, inferior com base gibosa; calcar menor a maior que o lábio inferior. Cápsula ovoide ou globosa.

Material selecionado: Araruama, Praia do Sossego (próximo à Praia Seca), alagado próximo às margens da lagoa de Araruama, ca. de $14 \mathrm{~km}$ da Rodovia Amaral Peixoto (entrada para praia seca), 7.III.1999, fl. e fr., R.M. Lisboa \& C.B. Moreira 21 (R). Arraial do Cabo, Praia do Pontal, 2.III.1951, fl. e fr., L.E. Mello Filho 1220 (R). Cabo Frio, Restinga de Cabo Frio, 9.X.1968, fl., D. Sucre 3888 (RB). Cachoeira de Macacu, Guapiaçu, Reserva Ecológica de Guapiaçu (REGUA) Fazenda São 
José, Lago 1, 22²7'10,1”S; 4246'22,4”W, 31 msm, 27.VIII.2011, fl., A.A.M. Barros et al. 4362 (RFFP). Campos dos Goytacazes, Lagoa de Cima, 19.VII.1975, fl., A.L. Peixoto 541 (RB). Carapebus, Restinga de Carapebus, Lagoa Comprida, 13.IX.1995, f1., M.G. Santos 415 (RB). Casimiro de Abreu, próximo a Rio das Ostras, Rod. RJ-106, Km 147, 20.III.1979, fl., G. Martinelli 5683 (RB). Itatiaia, III.1937, fl., A.C. Brade 15644 (RB); Macaé, Lagoa de Carapebus, 25.VIII.1982, fl., D. Araujo et al. 5189 (GUA); Magé, Antiga Fazenda da Fábrica de Papel, próximo do Rio do Bananal, 25.X.1982, fl., M.B. Casari et al. 775 (GUA). Maricá, Restinga de Maricá, C.P. Bove et al. 400 (R). Mauá, 16.I.1887, fl. e fr., Schawacke (R 3593). Nova Friburgo, Serra de Friburgo, meio da Serra, 10.VIII.1975, fl. e fr., P. Occhioni 7678 (RFA). Petrópolis, Parque Santana próximo à Serra de Petrópolis, 25.III.1079, fl. e fr., $P$. Occhioni 8776 (RFA). Quissamã, Estrada para Visgueiro, 17.VII.2007, fl., A. Moreira et al. 59 (R). Resende, Parque Nacional de Itatiaia, Caminho para o Rebouças, 26.IX.1980, est., M.B. Casari 368, (GUA). Rio de Janeiro, Restinga de Jacarepaguá, ao lado noroeste da Pedra de Itaúna, 16.VI.1969, fl., D. Sucre 5340 (RB). São Francisco de Itabapoana, Gargaú, 21.VIII.2003, fl., C.N. Fraga 1034 (RB). Saquarema, Praia Seca, 3.III.1999, fl., C.P. Bove 421 et al. (R). Silva Jardim, Poço d'Anta, 17.IX.1976, fl., M.C. Viana et al. 895 (GUA). Teresópolis, 19.VII.1961, fl., A. Abendroth 1803 (HB).

Espécie pantropical. No Rio de Janeiro: H36, L35, N30, N31, O4, O18, O24, P4, P5, P17, P27, Q17, Q20, Q25, T20, T23, T24, U16, U27. Semelhante a Utricularia foliosa, distingue-se pelo pedicelo sempre ereto, com as partes vegetativas e escapos verde-claros e rizoide, quando presentes, com ramos recurvados.

2.5. Utricularia hydrocarpa Vahl, Enum. Pl. 1. 200. 1804. Fig. 1i

Erva aquática. Rizoides ausentes. Estolões presentes. Folhas filiformes, repetidamente bifurcada, últimos segmentos capilares, curtos e setulosos, no estolão, 8-10 mm compr.; utrículos numerosos. Inflorescência laxa, $1-6 \mathrm{~cm}$; escamas ausentes; brácteas basifixas, ovadas a largoovadas; bractéolas ausentes; flores dimórficas. Flores rosadas com mácula amarela, até $10 \mathrm{~mm}$ compr.; pedicelo ereto em flor, subereto em fruto; sépalas subiguais, ovadas ou largo-ovadas, base decorrente, 2,3-4 mm compr., superior com ápice obtuso, inferior levemente truncado, crenado ou emarginado; lábio superior da corola levemente circular, inferior transversalmente elíptico, base gibosa, ápice emarginado; calcar cônico, menor que lábio inferior; flor cleistógama na base do escapo, pedicelo reflexo. Cápsula ovoide ou globosa.
Material examinado: Campos dos Goytacazes, Lagoa Feia, Coroa de Algodão, 7.IV.1979, est., D. Araujo et al. 3129 (GUA). Campos dos Goytacazes, Lagoa Feia, próximo à Lagoa da Samambaia, 7.VI.1979, est., $D$. Araujo et al. 3128 (GUA)

Material adicional examinado: SÃO PAULO: São José dos Campos, Banhado, 26.IV.1998, fl., C.P. Bove et al. $301(\mathrm{R})$.

Ocorre na América Tropical. No Brasil, do Norte ao Sudeste. No Rio de Janeiro foi encontrada apenas na Lagoa Feia (L35). É distinta das demais pela flor cleistógama próxima à base do escapo.

2.6. Utricularia longifolia Gardn. London J. Bot. 1: 545. 1842. Fig. $1 \mathrm{j}-1$

Erva litófita ou terrestre paludosa. Rizoides e estolões presentes. Folhas rosuladas na base do escapo, 11-105 cm compr., lâminas lanceoladas, não peltadas, multinérveas. Inflorescência simples, glabra; escapo 35-100 cm; escamas, bráctea e bractéolas basifixas, não auriculadas, ovadodeltóides, margem inteira; bractéolas livres, lineares. Flores roxas, 1,5-2,5(-3,3) cm compr., pedicelo ereto na flor e fruto; sépalas subiguais, 4-11 mm compr., margem minutamente denticulada; lábios da corola inteiros, arredondados, inferior maior, giba conspícua; calcar pouco menor que o lábio inferior. Cápsula globosa.

Material selecionado: Angra dos Reis, Parque Estadual Ilha Grande, Vila Dois Rios, na Cachoeira Mãe-d'Água, fl., A.A.M. Barros et al. 1363 (RFFP). Rio de Janeiro, Estrada das Paineiras, 27.V.1992, fl., C.P. Bove et al. 86 (R). São José do Vale do Rio Preto, Pedra das Flores 9.IX.1933, fl., P. Santos 186 (RB).

Endêmica da mata atlântica, da Bahia a São Paulo. No Rio de Janeiro: M19, T15, U7. Caracteriza-se pelo grande porte, possui as maiores folhas do gênero.

2.7. Utricularia nelumbifolia Gardn. Icon. P1. 6: t. 504.1843.

Fig. $1 \mathrm{~m}$

Erva epífita. Rizoides ausentes. Estolões presentes. Folhas ao longo dos estolões, 15-65(-90) cm compr., peltadas, orbiculares, multinérveas. Inflorescência glabra; 30-110 cm; escamas, bráctea e bractéolas basifixas, não auriculadas, de ovadas a lanceoladas, margem inteira; bractéolas livres. Flores violáceas, 3-5,5 cm compr., pedicelo ereto na flor e fruto; sépalas subiguais, glabras, $1-2 \mathrm{~cm}$ compr.; lábio superior da corola inteiro, inferior 3-lobado, giba conspícua; calcar curvo, subulado, maior que o lábio inferior. Cápsula ovoide.

Material examinado: Nova Friburgo, Cônego, Pedra do Imperador, 16.VI.2004, fl. e fr., R.C. Forzza 3420 (RB). Petrópolis, Km 20 da Itaipava-Teresópolis, 24.II.1963, 
fl., C.F.J. Pabst 7307 (HB). Santa Maria Madalena, Pedra Dubois, 28.II.1934, fl., S. Lima 3269 (RB). Teresópolis, Serra dos Órgãos, faz. Dr. Portugal, 27.XI.1948, fl., A.C. Brade 19468 (RB).

Endêmica do Brasil ocorrendo apenas nos estados de Minas Gerais, Espírito Santo e Rio de Janeiro (L29, O19, O23, P17). Caracteriza-se pelo formato das folhas.

\subsection{Utricularia nephrophylla Benj. in Martius Fl.} Bras. 10: 247. 1847.

Fig. $1 n$

Erva litófita. Rizoides e estolões presentes. Folhas ao longo dos estolões, 0,3-2,9 cm compr., reniformes, multinérveas. Inflorescência, glabra; 10-30 cm; escamas, bráctea e bractéolas basifixas, não auriculadas, de lineares a elípticas, margem inteira; bractéolas livres. Flores brancas a liláses, 0,9-1,6 cm compr., pedicelo ereto na flor e fruto; sépalas subiguais, glabras, 4,0-5,4 cm compr.; lábio superior da corola inteiro, inferior 3-lobado, giba conspícua; calcar pouco menor que o lábio inferior. Cápsula globosa.

Material selecionado: Teresópolis, Serra dos Órgãos, Campo das Antas, 26.XII.1952, fl., F. Markgraf 10474 (RB). Nova Friburgo, Monserrat, 30.IV.1923, fl., M.C.V. Bandeira (RB 22625). Petrópolis, entre Araras e Vale das Videiras, Morro do Cuca, Campos de Altitude, 15.V.1986, fl., G. Martinelli 11586 (RB). Rio de Janeiro, Estrada do Sumaré, 11.XII.2011, fl. e fr., A.M. Donza 135 (R). Santa Maria Madalena, Pedra Dubois, 28.II.1934, fl., S. Lima 13270 (RB). Teresópolis, Parna Serra dos Órgãos, prope Abrigo 4, 28.IV.1962, fl. e fr., E. Fromm et al. $1216(\mathrm{R})$.

Endêmica do Brasil, ocorre nos estados da Bahia, Minas Gerais, Espírito Santo, Rio de Janeiro (L29, O19, O23, P17, U16) e São Paulo. Caracteriza-se pelo pequeno porte, formato das folhas, tamanho do calcar e formato da semente. Os espécimes coletados no Município do Rio de Janeiro apresentam corola branca, enquanto as coletadas nas demais localidades do estado apresentam corola lilás.

2.9. Utricularia olivacea $\mathrm{C}$. Wright ex Griseb., Cat. P1. Cub. 161. 1866.

Fig. 10

Erva aquática. Rizoides ausentes. Estolões capilares utriculíferos. Folhas ausentes. Inflorescência 0,5-1 $\mathrm{mm}$ compr.; escamas ausentes; bráctea basifixa, depresso-ovada ou transversalmente oblonga, 0,5-0,8 mm compr.; bracteolas ausentes. Flores brancas, 1,5-3 mm compr.; pedicelo ereto em flor e fruto; sépalas subiguais, glândulas sésseis na base, margem inteira em flor e denticulada em fruto, cupuliformes, arredondadas; lábio superior da corola convexo, lábio inferior côncavo, corola 1,5-3 mm compr., calcar inconspícuo, arredondado ou ausente. Cápsula cilíndrica.

Material selecionado: Carapebus, Lagoa Comprida, 12.IX.2005, fl., C.P. Bove et al. 1592 (R). Macaé, Lagoa Comprida, 24.VIII.1982, fl., D. Araujo et al. 5182 (GUA). Rio de Janeiro, Baixada de Jacarepaguá, FEEMA, 17.VII.1984, Bianchi est. (GUA 27237).

Material adicional examinado: GOIÁS: Alto Paraíso de Goiás, Parque Nacional da Chapada dos Veadeiros, 3.VI.2009, fl. e fr., P.C. Baleeiro et al. 25 (R).

Ocorre nas Américas. No Brasil é encontrada nos estados do Amazonas, Goiás, Minas Gerais e Rio de Janeiro. No Rio de Janeiro (N30, O30, U16) somente na Restinga. Distingue-se por apresentar sépalas com margem inteira na flor e profundamente laciniada no fruto e estolão capilar com ramos alternos.

2.10. Utricularia poconensis Fromm, Bradea 4: 139140. 1985.

Fig. $2 \mathrm{a}-\mathrm{b}$

Erva aquática. Rizoides ausentes. Estolões presentes. Folhas no estolão, filiformes, repetidamente bifurcada, 2 cm compr.; utrículos numerosos. Inflorescência glabra, laxa, 2,5-15(-20) cm compr.; escamas basifixas, largo-ovadas, base inteira ou auriculada; bráctea semelhante à escama, bractéolas ausentes. Flores rosas ou liláses, com mácula amarela, 6-8 mm compr.; pedicelo ereto na flor, reflexo no fruto; sépalas subiguais, glandulares, inteiras, nervuras inconspícuas, ovadas a largo-ovadas, ápice obtuso ou emarginado; lábio superior da corola até duas vezes maior que sépala superior; lábio inferior com base gibosa, pubescente; calcar cônico, levemente menor ou maior que o lábio inferior. Cápsula globosa.

Material selecionado: Campos dos Goytacazes, próximo ao Porto de Ponta Grossa de Fidalgos, 15.VII.1981, fl., M.B. Casari 630 (GUA). Carapebus, Lagoa de Jurubatiba (antiga Cabiúnas), 13.IX.2005, fl., C.P. Bove et al. 1596 (R). Macaé, lagoa de Cabiúnas, em água doce, 11.VIII.1980, fl., D. Araujo 3920 (GUA).

Material adicional examinado: TOCANTINS: Formoso do Araguaia, 15.IV.2006, fl., C.P. Bove 1667 (R).

Ocorre na América do Sul. No Brasil é bem distribuída. No Rio de Janeiro ocorre na Restinga (L35, N30). Semelhante a U. hydrocarpa, diferenciase por ser mais robusta e ausência de flor cleistógama na base do escapo.

2.11. Utricularia praelonga A.St.-Hil. \& Girard, Compt. Rend. Hebd., Séances Acad. Sci., Ser. D. 7: 870. 1838.

Fig. 2c

Erva terrestre. Rizoides presentes ou ausentes. Estolões utriculíferos. Folhas na base do escapo, 

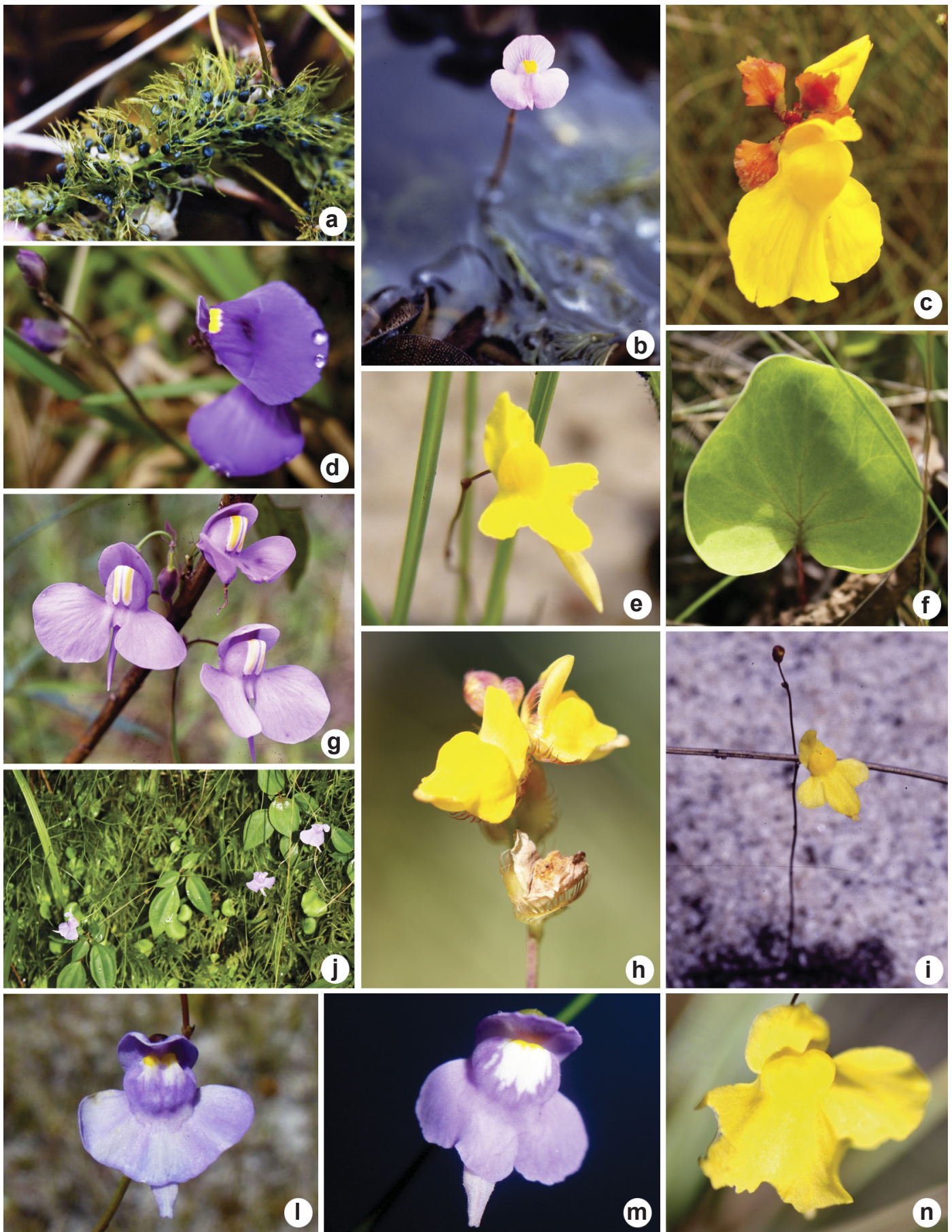

h
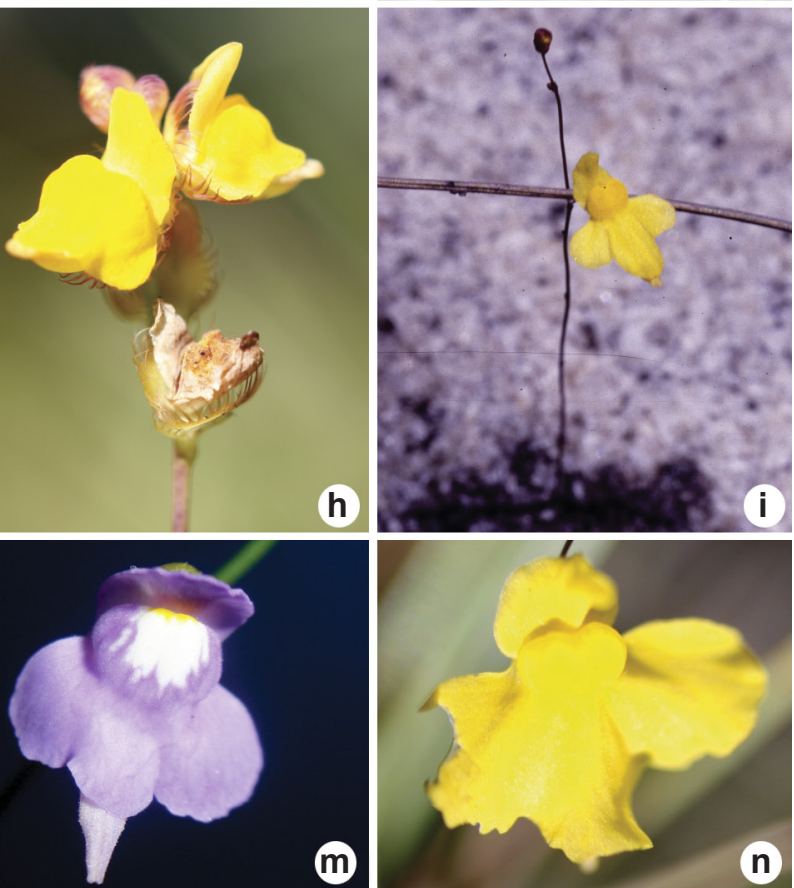

Figura 2 - a-b. Utricularia poconensis - a. folha com utrículos; b. flor (Bove et al. 1596). c. Utricularia praelonga flores (Oliveira \& Moura 148). d. Utricularia pubescens - flor (Condack \& Vasco 624). e. Utricularia pusilla - flor. f-g. Utricularia reniformis - f. folha (Pellegrini 193); g. flores. h. Utricularia simulans - flor. i. Utricularia subulata - flor (Bove et al. 1616). j-1. Utricularia tricolor - j. hábito (Pellegrine 214); 1. flor (Bove et al. 422). m. Utricularia tridentata - flor. n. Utricularia triloba - flor (Bove et al. 2088).

Figure 2 - a-b. Utricularia poconensis - a. leaf with traps; b. flower (Bove et al. 1596). c. Utricularia praelonga - flowers (Oliveira \& Moura 148). d. Utricularia pubescens - flower (Condack \& Vasco 624). e. Utricularia pusilla - flower. f-g. Utricularia reniformis - f. leaf (Pellegrini 193); g. flowers. h. Utricularia simulans - flower. i. Utricularia subulata-flower (Bove et al. 1616). j-1. Utricularia tricolor -j. habit (Pellegrine 214); 1. flower (Bove et al. 422). m. Utricularia tridentata-flower (Silva). n. Utricularia triloba-flower (Bove et al. 2088). 
lineares, coriáceas, $3 \mathrm{~cm}$ compr. Inflorescência glabra, laxa a levemente congesta, 25-48(-75) cm compr.; escamas basifixas, ovadas, laciniadas; brácteas semelhantes às escamas; bractéolas menores que a bráctea, lanceoladas, margem inteira ou laciniada. Flores amarelas, $1-2 \mathrm{~cm}$ compr.; pedicelo ereto em flor e fruto; sépalas desiguais, papilosas, margem erosa-denticulada, superior largo-ovada, base subcordada e ápice agudo, 2,8-3,2(-5) mm compr., inferior ovada, base arredondada e ápice emarginado, 2,5-3 $\mathrm{mm}$ compr.; lábios da corola ovados a amplamente largo-ovados, giba saliente e ápice inteiro ou levemente 3-lobado; calcar levemente curvado para cima, cônico, mesmo tamanho ou levemente maior que o lábio inferior. Cápsula globosa.

Material examinado: Itatiaia, Mont'serrat, Parque Nacional do Itatiaia, 15.X.1922, fl., J.G. Kuhlmann (RB 326499).

Material adicional examinado: GOIÁS: Alto Paraíso de Goiás, rodovia para São Jorge, chácara Portal da Chapada, 13.II.2005, fl., J.F.B. Pastore 1263 (CEN). Bahia: Ventura, 19.XI.2009, f1. A. Oliveira \& R. Moura 148 (R).

Ocorre na Argentina, Brasil e Paraguai. No Brasil, da Bahia ao Rio Grande do Sul. É rara no estado do Rio de Janeiro, com apenas um antigo registro no PARNA Itatiaia (P4). Diferencia-se pelas brácteas laciniadas e sépalas papilosas com margem eroso-denticulada.

2.12. Utricularia pubescens Sm., in Rees, Cycl. 37 n. 53. 1819.

Fig. 2d

Erva terrestre. Estolões utriculíferos. Folhas peltadas, lâminas orbiculares, 2-4 mm diâm., utriculíferas Inflorescência simples, pubescente, $25-60 \times 0,3 \mathrm{~mm}$; escamas ovadas, pilosas; bráctea e bractéolas peltadas, pilosas, $0,8-1,2 \mathrm{~mm}$ compr. Flores roxas ou lilases, com mácula amarela na giba, pubescentes, 5-6 mm compr., pedicelo ereto na flor e no fruto; sépalas subiguais, pubescentes, ovadas, sépala superior $2,5 \mathrm{~mm}$ compr., inferior 1,8 mm compr.; lábio superior da corola oblongo, levemente maior que a sépala superior, lábio inferior depresso-obovado, giba inconspícua; calcar subulado, menor, igual ou maior que o lábio inferior da corola. Cápsula globosa.

Material selecionado: Itatiaia, Parque Nacional do Itatiaia, XII.2009, fl., J. Condack \& A.G. Vasco 624 (R). Teresópolis, Parna Serra dos Órgãos, entre os abrigos 3 e 4, 29.IV.1962, fl., E. Fromm et al. 1232 (R).

Pantropical. No Brasil, nos estados do Amazonas, Ceará, Goiás, Mato Grosso, Minas Gerais, São Paulo e Rio de Janeiro (P4, O18).
Ocorre em barrancos úmidos cobertos por musgos ao lado de córregos, destaca-se pela lâmina foliar circular peltada bem menor que da epífita $U$. nelumbifolia. Representantes de U. pubescens sem folhas podem ser distintos pelo ponto de inserção das brácteas e bractéolas, próximo à base e não próximo ao centro como as demais espécies com brácteas peltadas. Apesar desta espécie possuir flores alvas, não há registro desta coloração no Rio de Janeiro.

2.13. Utricularia pusilla Vahl., Enum. Pl. 1. 202. 1804.

Fig. 2e

Erva terrestre. Rizoides presentes. Estolões utriculíferos. Folhas na base do escapo e estolão, lineares a largo-obovadas, 4-7(-20) $\mathrm{mm}$ compr. Inflorescência glandular na base; 3,5-16,5 cm compr.; escamas peltadas, estreito-ovadas; margem frequentemente denticulada; brácteas peltadas, elípticas ou largo-elípticas; bractéolas ausentes. Flores amarelas, 4-6 mm compr.; pedicelo ereto em flor e fruto; sépalas subiguais, glabras, inteiras, ovadas, arredondadas ou levemente obovadas, nervuras inconspícuas não convergentes no ápice, sépala inferior maior em fruto; lábio superior da corola inteiro, pelo menos duas vezes maior que a sépala superior; lábio inferior 3-lobado; calcar subulado, reto, até duas vezes maior que lábio inferior da corola. Cápsula globosa.

Material examinado: Santa Maria Madalena, Morro da antena, Mata do Criminoso, propriedade do Sr. João Batista Bizzo, 21.IV.2008, fl., M.M. Saavedra 714 (RB). Teresópolis, 29.IV.1917, fr., A.J. Sampaio 2367 (R). Material adicional examinado: GOIÁS: Alto Paraíso de Goiás, GO-118, entre Alto Paraíso de Goiás e Teresina de Goiás, Km 196, 5.VI.2009, fl., P.C. Baleeiro et al. 39 (R).

Ocorre do Sul do México à América do Sul. No Brasil, do norte ao sudeste. No Rio de Janeiro é encontrada na floresta ombrófila densa montana (L29, O18). Distingue-se pelo calcar alongado e reto, sépala inferior no fruto maior que a sépala superior.

2.14. Utricularia reniformis A.St-Hil. Voy. Rio de Janeiro \& Minas Gerais 1: 224. 1830.

Fig. $2 \mathrm{f}-\mathrm{g}$

Erva litófita, terrestre paludosa ou epífita. Rizoides ausentes. Estolões presentes. Folhas ao longo dos estolões, 1-62(-87) cm compr., reniformes, multinérveas. Inflorescência, glabra; 28-70 cm; escamas, brácteas e bractéolas basifixas, não auriculadas, elipsóides a ovadas, margem inteira; bractéolas livres. Flores roxas, 2,1-3,8(4,2) $\mathrm{cm}$ compr., pedicelo ereto na flor e fruto; sépalas 
subiguais, glabras, margem inteira, $0,9-1,5 \mathrm{~cm}$ compr.; lábio superior da corola inteiro, inferior 3-lobado, giba conspícua; calcar maior que o lábio inferior. Cápsula globosa.

Material selecionado: Itatiaia, estrada entre o Abrigo Rebouças e o inicio da trilha para as Prateleiras, 21.X.2009, fl., R. Couto 280 (R). Petrópolis, Morro do Marco, 27.VIII.2008, fl., M. Nadruz 2222 (RB). Resende, Parque Nacional de Itatiaia, próximo ao abrigo Rebouças, 26.VI.1983, fl., M.B. Casari 1038 (GUA). Rio de Janeiro, Serra da Mantiqueira, 3.III.1931, fl., Kaempfe (RB87274). Santa Maria Madalena, Parque Estadual do Desengano, Pedra do Desengano, vertente nn. campos de altitude, 20.XII.1988, G. Martinelli 13234 (RB). Teresópolis, Parque Nacional da Serra dos Órgãos, 10.XII.2007, fl., R. Polini 244 (R).

Endêmica do Brasil, ocorre nos estados da região sudeste e sul, no Rio de Janeiro é encontrada na floresta ombrófila densa montana (L29, O18, P4, P5, P17, U16). Caracteriza-se pelo porte robusto e folhas reniformes de pecíolo longo. Pode ocorrer em associação com bromélias, sendo mais comum em solo turfoso. Studnička (2009) detectou diferenças entre as populações da Serra dos Órgãos e da Serra da Mantiqueira no que tange à morfologia do utrículo; tamanho, textura e coloração das folhas e flores; morfologia da semente e germinação que resultaram na descrição de U. cornigera para a população da Serra dos Órgãos. Entretanto tais características não foram aqui observadas. Optamos por não considerar esta espécie, entretanto, estudos de populações devem ser empreendidos para uma análise mais acurada da identidade deste táxon.

2.15. Utricularia simulans Pilg., Notizbl. Königl. Bot. Gart. Berlin 6: 189. $1914 . \quad$ Fig. 2h

Erva terrestre paludosa. Rizoide e estolões presentes. Folhas rosuladas na base do escapo ou menos frequente no estolão, 5-8 mm compr., lâminas lineares ou estreito-obovadas, uninérveas; utrículos ca. 0,2-0,3 mm diâm., um apêndice dorsal e um ventral bífido. Inflorescência simples ou ramificada, glabra, geralmente congesta; escapo $5 \mathrm{~cm}$; escamas e brácteas basifixas, auriculadas, ovadas a largo-ovadas, margem fimbriada; bractéolas basifixas, não auriculadas, ovadas, margem fimbriada, bem maiores que as brácteas, inseridas próximo às sépalas. Flores amarelas, até $1 \mathrm{~cm}$ compr., pedicelo ereto na flor e fruto; sépalas subiguais, 2-4 mm compr., fimbriadas; lábios da corola inteiros, arredondados, inferior pouco maior, giba conspícua; calcar maior que o lábio inferior. Cápsula globosa.

Material examinado: Cabo Frio, praia de Cabo Frio. 22.II.1964, fl,. Segadas-Vianna 1419-1420c (R).

Material adicional examinado: TOCANTINS: TO476, Dianópolis, Rio da Conceição a $45 \mathrm{~km}$ do trevo, 7.VI.2009, fl., P.C. Baleeiro et al. 63 (R).

Ocorre na África e nas Américas, no Brasil tem ampla distribuição. Registrada no Estado do Rio de Janeiro por apenas uma coleta na restinga de Cabo Frio (T27), provavelmente extinta no local devido à intensa pressão imobiliária. É frequentemente encontrada em solos arenosos do nível do mar a $1575 \mathrm{~m}$ alt. (Taylor 1989), geralmente em campos rupestres e campinas, contudo a registros de ocorrência para restingas no litoral do Pará. Distingue-se das outras espécies ocorrentes no Rio de Janeiro pelas escamas, brácteas, bractéolas e sépalas fimbriadas.

2.16. Utricularia subulata L., Sp. Pl. 1: 18 . 1753.

Fig. $2 \mathrm{i}$

Erva terrestre ou paludosa. Rizoides e estolões utriculíferos. Folhas lineares, uninérveas, utriculíferas, 10-30 mm compr. Inflorescência glabra, 40-190 mm compr.; escamas peltadas, elípticas, ápice agudo; brácteas semelhantes às escamas, largo-elípticas; bractéolas ausentes. Flores amarelas, 5-10 $\mathrm{mm}$ compr., pedicelo ereto na flor e fruto; sépalas subiguais, glabras, ovadas a circulares, margem inteira, ápice arredondado a subtruncado, nervuras do cálice não proeminentes e não convergentes no ápice; lábio superior da corola inteiro e inferior trilobado, giba proeminente; calcar maior ou menor que o lábio inferior. Cápsula globosa.

Material selecionado: Arraial do Cabo, Estrada BR5 para Arraial do Cabo, 30.XII.1962, fl., E. Fromm et al. 1328 (HB). Cabo Frio, Praia do Pontal, 1953, fl., F. Segadas-Vianna et al. 1189 (R). Carapebus, próximo ao Canal de Macaé e Campos, 10.II.2009, fl., P.C. Baleeiro et al. 3 (R). Macaé, Lagoa de Carapebus, 13.II.1980, fl., D. Araujo et al. 3531 (GUA). Maricá, Restinga de Maricá, 27.IX.1988, fl., R. Marquete 146 (RB). Quissamã, Alagado na bifurcação para Visgueiro, C.P. Bove et al. 1616 (R). Rio de Janeiro, Restinga de Jacarepaguá, 16.VII.1966, fl. e fr., C.F.J. Pabst et al. 8935 (HB). São João da Barra, 27.XII.1967, fl. e fr., M. Emmerich 1892 (R).

Cosmopolita, no Brasil tem ampla distribuição. No Rio de Janeiro ocorre na Restinga em solo brejoso arenoso (J36, N30, T20, T27, U16, U27). Sua amplitude morfológica dificulta a distinção entre as espécies mais próximas dentro da seção. 
2.17. Utricularia tricolor A.St.-Hil., Voy. Distr. Diam. 2: 418. 1833.

Fig. $2 \mathrm{j}-1$

Erva terrestre. Rizoides e estolões utriculíferos. Folhas rosuladas ou não, obovadas a circulares, multinérveas, base atenuada, $5-55 \mathrm{~mm}$ compr. Inflorescência laxa; (24-)30-60 cm compr.; escamas basifixas, deltóides; bráctea semelhante às escamas; bractéolas basifixas, unidas à bráctea na base. Flores violáceas a liláses, mácula amarela e branca, $12 \mathrm{~mm}$ compr.; pedicelo ereto em flor e fruto; sépalas desiguais, glabras, inteiras; superior com ápice agudo ou irregularmente crenado, 3 $\mathrm{mm}$ compr.; inferior ápice emarginado, $1,8 \mathrm{~mm}$ compr.; lábio superior da corola duas vezes maior que a sépala; lábio inferior com base gibosa, ápice arredondado, inteiro ou crenado; calcar estreitocônico, levemente curvado para cima, igual ou levemente maior que o lábio inferior. Cápsula globosa.

Material selecionado: Araruama, Praia Seca, a $15 \mathrm{~km}$ após a entrada para Praia Seca, 3.II.1999, fl. e fr., C.P. Bove 422 (R). Cabo Frio, entre Lagoa de Araruama e Praia de Massambaba, brejo dos Espinhos, 20.XII.1982, fl., D.S. Pedrosa et al. 742 (GUA). Carapebus, praia entre Lagoa Paulista e Lagoa de Carapebus, 23.IV.1999, fl., C.P.R. Batista et al. 35 (R). Petrópolis, 12.IV.2012, fl., Pellegrini 214 (R). Quissamã, Lagoa Paulista, $L$. Senna-Vale et al. (R 208828). Saquarema, Praia do Sossego, 28.VIII.1999, fl., C.B. Moreira et al. 53 (R). Teresópolis, near border with Mun. Magé, $5 \mathrm{~km} \mathrm{SW}$ of Teresópolis, elev. c. $1000 \mathrm{~m}, 22^{\circ} 28^{\circ} \mathrm{S}$; 42 ${ }^{\circ} 59^{\prime} \mathrm{W}$, 28.XI.986, fl., G.L. Webster 25859 (R).

Ocorre na América do Sul. No Brasil é encontrada do Nordeste ao Sul do país, com predominância no Centro-Oeste. Diferencia-se pelas sépalas de tamanho desigual. Taylor (1989) considera a folha de $U$. tricolor como peciolada, no entanto, Souza \& Bove (2012) destacam que, na realidade, a base da lâmina apresenta um prolongamento atenuado semelhante a um pecíolo.

2.18. Utricularia tridentata Sylvén, Ark. Bot. 8(6): 28.1909 .

Fig. $2 \mathrm{~m}$

Erva terrestre paludosa. Rizoides e estolões presentes. Folhas rosuladas na base do escapo, circulares a obovadas, multinérveas, $8-24 \mathrm{~mm}$ compr. Inflorescência simples ou ramificada, pauciflora, glabra; 5,5-17,5 $\mathrm{cm}$; escamas, brácteas e bractéolas basifixas, não auriculadas, lanceoladas, margem inteira; bractéolas lineares, unidas às brácteas na base. Flores violáceas, 6-10 mm compr., pedicelo ereto na flor e fruto; sépalas desiguais, 1-3 mm compr., inteiras; lábio superior da corola inteiro, inferior 3-lobado, giba conspícua, por vezes 3-lobada; calcar maior que o lábio inferior. Cápsula globosa.

Material examinado: Itatiaia, Estrada Nova, $\mathrm{Km} \mathrm{15}$, V.1950, f1., A.C. Brade 20329 (RB). Teresópolis, Serra dos Órgãos, 12.XII.1891, fl., Ule (R14889). Teresópolis, Cachoeira do Paquequer, 1883, fl. e fr., A.J. Rodrigues (R97216).

Ocorre na Argentina, Brasil (do Rio de Janeiro, O19, P4 ao Rio Grande do Sul) e Uruguai. Semelhante a $U$. tricolor, caracteriza-se pelo seu pequeno porte, folhas circulares a obovadas, brácteas e bractéolas concrescidas na base, flor violácea e corola com lábio inferior trilobado. Apesar de protegida em Unidade de Conservação (PARNA Serra dos Órgãos e Itatiaia) parece extinta no Estado, com a última coleta há mais de 60 anos.

2.19. Utricularia triloba Benj., in Martius, Fl. Bras. 10: 248. 1847. Fig. 2n

Erva terrestre ou paludosa. Rizoides e estolões utriculíferos. Folhas lineares, até 4,5 cm compr.; utrículos não observados. Inflorescência uniflora, 10,5-13,5 cm compr.; escamas peltadas, elípticas, ápice agudo; brácteas semelhantes às escamas, amplamente elípticas; bractéolas ausentes. Flores amarelas, ca. $7 \mathrm{~mm}$ compr., pedicelo ereto na flor e fruto; sépalas subiguais, ovadas a circulares, inteiras, nervuras proeminentes convergentes no ápice; lábio superior da corola inteiro e inferior 3-lobado, giba proeminente; calcar maior ou menor que o lábio inferior. Cápsula globosa.

Material examinado: Itatiaia, nos campos brejos, 20.I.1873, fl. e fr., Glaziou $6630 b$ (R). Petrópolis, Serra dos Órgãos, Fazenda Bonfim, I.1973, fl. e fr., 1000 m chapada esquerda do Rio Bonfim, J. Barcia 600 (R).

Material adicional examinado: TOCANTINS: Rio da Conceição, TO-476, estrada Dianópolis - Rio da Conceição, Balneário Cachoeira, 7.VI.2009, fl., C.P. Bove et al. 2088 (R).

Ocorre na América Central (Belize e Trinidad e Tobago) e América do Sul. No Brasil é amplamente distribuída. No Rio de Janeiro é encontrada na floresta ombrófila densa montana (P4, P17). Pode ser confundida com U. subulata, distinguindo-se desta pelo cálice de ápice agudo com nervuras proeminentes, em oposição ao cálice de ápice obtuso com nervuras inconspícuas em $U$. subulata; além do ambiente (floresta ombrófila e restinga, respectivamente).

\section{Agradecimentos}

Aos curadores e equipe dos herbários GUA, $\mathrm{HB}, \mathrm{R}, \mathrm{RB}, \mathrm{RFA}$ e RBR. Ao Instituto Chico 
Mendes de Conservação da Biodiversidade, as licenças de coleta concedidas.

\section{Referências}

BFG. 2015. Growing knowledge: and overview of seed plant diversity. Rodriguésia 66: 1085-113.

Bove, C.P. \& Baleeiro, P.C. 2009. Lentibulariaceae. In: Stehmann, J.R.; Forzza, R.C.; Salino, A.; Sobral, M.; Costa, D.P. \& Kamino, L.H.Y. (org.). Plantas da Floresta Atlântica. Jardim Botânico do Rio de Janeiro, Rio de Janeiro. Pp. 308-309.

Fleischmann, A.; Rivadavia, F.; Gonella, P.M. \& Heubl, G. 2011. A revision of Genlisea subgenus Tayloria (Lentibulariaceae). Phytotaxa 33: 1-40.

Fromm-Trinta, E. 1972. Flora ecológica de restingas do sudeste do Brasil XXI, Lentibulariaceae. Publ. Museu Nacional, Universidade Federal do Rio de Janeiro 21: 1-40.

Fromm-Trinta, E. 1973. Lentibulariaceae do estado da Guanabara, Brazil. Boletim do Museu Nacional, Série Botânica 42: 1-34.

Fromm-Trinta, E. 1981. Revisão do gênero Genlisea St.Hil. (Lentibulariaceae) no Brasil. Boletim do Museu Nacional, nova série botânica 61: 1-21.
Fromm-Trinta, E. 1989. O gênero Utricularia L. no Brasil V. Espécies da região sudeste. Bradea 5: 267-274.

Fromm-Trinta, E. 1997. Lentibulariaceae. In: Marques, M.C.M. \& Martins, H.F. (eds.). Flora do estado do Rio de Janeiro. Albertoa 4: 67-109.

Müller, K.F. \& Borsch, T. 2005. Phylogenetics of Utricularia (Lentibulariaceae) and molecular evolution of the trnk intron in a lineage with high substitutional rates. Plant Systematics and Evolution 250: 39-67.

Souza, P.C.B. \& Bove, C.P. 2012. Lentibulariaceae. Flora dos estados de Goiás e Tocantins. Vol. 42. Coleção Rizzo. Universidade Federal de Goiás, Goiânia. 136p.

Souza, P.C.B. \& Bove, C.P. 2013. Flórula do Parque Nacional da Restinga de Jurubatiba, Rio de Janeiro, Brasil: Lentibulariaceae. Arquivos do Museu Nacional 69: 95-99.

Studnička, M. 2009. Brazilian bladderwort Utricularia reniformis is a blend of two species. Thaiszia Journal of Botany, Košice 19: 131-143.

Taylor, P. 1989. The genus Utricularia - a taxonomic monograph. Kew Bulletin Additional Series 14: 1-724.

Taylor, P. 1991. The genus Genlisea. Carnivorous Plant Newsletter 20: 20-26. 
Lista de exsicatas

Abendroth, A. 1803 (2.4); Angeli, C. 283(2.3), 197(2.6). Araujo, D. 3307(2.1), 4244(2.1), 3118 (2.2), 3439 (2.2), $3068(2.2), 5502$ (2.2), $1086(2.2), 3065(2.4), 3125(2.4), 4359(2.4), 4253(2.4), 5182$ (2.9), 5504(2.4), 3304a (2.4), 5737(2.4), 1056(2.4), 3129 (2.5), $3128(2.5)$. Araujo, D. et al. 3128 (2.5), 3129 (2.5), 3531 (2.16), 3920 (2.10), 4893 (2.16), 4995 (2.2). Augusto, J. s.n. (R212310) (2.4). Amorim, A.M.A. 65 (2.2). Atal, F. 345(2.4). Baleeiro-Souza, P.C. et al. 3 (2.16), 7 (2.16), 25 (2.9), 39 (2.13), 63 (2.15), 72 (2.17), 78 (2.3). Bandeira, M.C.V. s.n. (RB 22625) (2.8). Barcia, J.C. 600 (2.19), 605 (2.3), s.n. (R212311)(2.4). Barros, A.A.M. et al. 1363 (2.6), 4362 (2.4). Barros, A.A.M. \& Jascone, C.E. 3357 (2.2). Batista, C.P.R. et al. 35 (2.17). Bianchi s.n. (GUA 27237) (2.9). Bittencourt, H. 140 (2.4). Bove, C.P. et al. 86 (2.7), 124 (2.10), 301 (2.5), 409 (2.1), 422 (2.17), 439 (2.4), 447 (2.2), 456 (2.1), 464 (2.9), 754 (2.4), 1223 (2.2), 1401 (2.4), 1420 (2.2), 1592 (2.9), 1596 (2.10), 1598 (2.2), 1616 (2.16), 1667 (2.10), 1992 (2.2), 2088 (2.19), 2207 (1.1). Brade, A.C. 15642 (2.18), 15640 (2.18), 10777 (1.1), 12481 (1.1), 10978 (2.1), 15643 (2.3), 5856 (2.3), 18655 (2.3), 16634 (2.3), s.n. (R 24333 ) (2.3), 10752 (2.3), 15644 (2.4), s.n. (R97303) (2.6), 10972 (2.6), s.n. (R16700) (2.6), 20329 (2.18), 20534 (2.6). Camerik, A.M. 239 (2.3); 228 (2.3). Carauta, P. 1681 (2.6). Casari, M.B. 368 (2.4), 630 (2.10), 1038 (2.14). Casari, M.B. et al. 743 (2.2), 628 (2.2), 475(2.2), 533(2.2), 513(2.2), 485 (2.2), 627(2.4), 501(2.4), 980 (2.10). Castellanos, A. 25652 (2.8). Condack, J. \& Vasco, A.G. 624 (2.12). Correia 694 (2.18). Couto, R. 280 (2.14). Donza, A. 135 (2.8), 136 (2.3). Emmerich, M. s.n (HB) (2.4), s.n. HB 15716 (2.6), 1892 (2.16). Eindisch, P.G. 884 (2.8). Farney, C. \& Landolt, E. 378 (2.2). Fernando, L. 02 (2.3). Fevereiro, P.C.A. 66 (2.2). Fraga, C.N. 1028 (2.2), 1034 (2.4). Fromm, E. et al. $1216(2.8), 1226(2.6), 1328$ (2.16), 1232 (2.12), 1985 (2.8). Fromm, E. \& Santos, E. 1258 (2.4). Galvão, R. 663 (2.2). Garcia, J. s.n. (R212308) (2.4). Glaziou 16233 (1.1), 12928 (2.2), 11129 (2.3), 6630b (2.19), 6036a (2.4), 1535 (2.6), s.n. (R97242) (2.6). Glaziou \& Saldanha s.n. (R 97258) (2.6). Gentry, A.H. 934 (2.3). Góes, O.C. 1165 (2.3). Gomes, F.P.M. s.n. (R 102454) (2.6). Honorina, M. 49 (2.4), 45 (2.6). Hunt, D.R. 6467 (2.3), 5429(2.6). Huszar, V. s.n. (R 212309) (2.2). Jesus, Lúcia e Loreley s.n (R134890) (2.3); s.n (RB 41439) (2.6). Kaempfe s.n (2.14). Koehler, S. \& Moreira, C.B. 1 (2.2). Kuhlmann, J.G. 140 (2.6) s.n. (R 97276) (2.3), s.n. (R112012) (2.6), s.n (RB 41439) (2.6), s.n (RB 41440) (2.6), s.n. (RB 326499) (2.11). Labouriau, A. 289 (2.6). Lima, S. 13270 (2.8), 14227 (2.13). Lisboa, R.M. 15 (2.1), 17 (2.4). Lisboa, R.M. \& Moreira, C.B. 19 (2.1), 21 (2.4). Lourteig, A. 1852 (2.3). Lutz, B. 1066 (2.2), 2010 (2.3), s.n. (R 121254) (2.3), 1590 (2.4), s.n. (R 130829) (2.4), 1684 (2.4), 1789 (2.4), 623 (2.6), s.n. (R 15680) (2.6). Luz, A. s.n. (2.3). Markgraf, F. 10474 (2.8). Marquete, R. 146 (2.16), 148 (2.1). Martinelli, G. 5683 (2.4), 8819 (2.2), 11586 (2.8), 11804 (2.3), 13234 (2.14), 13387 (2.3), 16048 (2.17). Martins, V.L.C. s.n. (2.4). Mello Filho, L.E. 1220 (2.4). Moreira, A. et al. 59 (2.4), 62 (2.16)64 (2.4), 89 (2.16). Moreira, C.B. 42 (2.4). Moreira, C.B. et al. 53 (2.17). Moura, R. 219 (2.6). Nadruz, M. 1747 (2.3), 2222 (2.14). Occhioni, P. 1103 (2.6). Oliveira, R.F. s.n. (GUA 33634) (2.4). Pabst, G.F.J. 5644 (2.3), 6782 (2.8), 6933 (2.8), 8935 (2.16). Passarelli, A. 11 (2.2). Pastore, J.F.B. 1263 (2.11). Pedrosa, D.S. et al. 742 (2.17). Pedrosa, D.S. \& Casari, M.B. 848 (2.4). Peixoto, A.L. 541 (2.4). Pellegrini, M.O.O. 193 (2.14), 214 (2.17). Pereira, C. 7596 (2.2), 64 (2.2). Pereira, E. 176 (2.3), 290 (2.8), 7178 (2.8), 7186 (2.3), s.n. (HB6202). Polini, R. 244 (2.14). Rizzini 247 (2.3). Rodrigues, A.J. s.n. (R97216) (2.18). Saldanha, J. s.n (R97218) (1.1), s.n. (R 97214) (2.6). Sampaio, A. 2367 (2.13), 2937 (2.2), 2956 (2.2), 7889 (2.2), 2755 (2.4), 3127 (2.4), 2789 (2.4), 3124 (2.4), 2654, 2534 (2.4), s.n. (R 97293) (2.4), s.n. (R 97278) (2.4). Santos, L. 186 (2.6). Santos, M.G. 415 (2.4), 417 (2.2), 457 (2.1). Santos, E. \& Emmerich, M. s.n. (R) (2.4). Sarahyba, L.S. s.n. (GUA 26552) (2.3). Saavedra, M.M. 714 (2.13). Schwacke s.n. (R 97367) (2.4). Schwaike, B. s.n. (R 3589) (2.6). Schreiner s.n. (R 97363) (2.6). Segadas-Vianna, F. et al. 857(2.1), 1188 (2.4), 1189 (2.16), 1419-1420 (2.15); 4639 (2.4). Senna-Vale, L. s.n (R 208828) (2,18). Silva, I.M. 243(2.1), 246(2.1), 277 (2.4). Silva, J.G. 4018 (2.4). Silva, Z. 92 (2.3), 14 (2.4). Silveira, C.P. 624 (2.6). Smith, L.B. 6627(2.2). Souza, A. 28011 (2.1), 2800 (2.4). Souza, D. 507 (2.8). Sousa, L.O.F. 352 (2.4). Strang, H.E. 48 (2.3), 227 (2.8). Sucre, D. 1017 (2.2), 1335 (2.4), 1453 (2.8), 1715 (2.8), 2787 (2.3), 3888 (2.4), 5340 (2.4), 6456 (2.4), 6519 (2.3), 10043 (2.6). Sucre, D. \& Braga, P.I.S. 2787 (2.3). Trinta, Z.A. 891 (2.6). Trinta, Z.A \& Fromm, E. 891 (2.3), 919 (2.4), 958(2.4). Ule, E. s.n. (R14889) (2.18), 110 (2.3), 216 (2.4) 126 (2.6). Viana, M.C. 270 (2.8), 354 (2.3), 895 (2.4), 1054 (2.2), s.n (GUA06056) (2.1). Vidal, J. 6621 (953) (2.3), 4873 (2.3), 6564 (2.3), 1233 (2.3), s.n. (R105605), (2.3). Webster, G.L. 25859 (2.17). Zippin, M. s.n. (GUA 31051) (2.4) (RUSU 295). 